\section{Pulsed-field profile diversities of Salmonella Enteritidis, S. Infantis, and S. Corvallis in Japan}

\author{
Koichi Murakami, ${ }^{1,2}$ Tamie Noda, ${ }^{2}$ \\ Daisuke Onozuka, ${ }^{3}$ Hirokazu Kimura, ${ }^{1}$ \\ Shuji Fujimoto ${ }^{4}$ \\ ${ }^{1}$ Infectious Disease Surveillance Center, \\ National Institute of Infectious Diseases, \\ Tokyo; ${ }^{2}$ Fukuoka Institute of Health and \\ Environmental Sciences, Fukuoka; \\ ${ }^{3}$ Department of Health Care \\ Administration and Management, \\ Kyushu University Graduate School of \\ Medical Sciences, Fukuoka; \\ ${ }^{4}$ Department of Health Sciences, Faculty \\ of Medical Sciences, Kyushu University, \\ Fukuoka, Japan
}

\section{Abstract}

The diversity of pulsed-field profiles (PFPs) within non-typhoidal Salmonella subtypes influences epidemiological analyses of Salmonella outbreaks. Therefore, determining the PFP diversity of each Salmonella serovar is important when evaluating current circulating strains. This study examined the PFP diversity of three important public health Salmonella enterica subspecies enterica serovars, $S$. Enteritidis $(\mathrm{n}=177), \quad S$. Infantis $(\mathrm{n}=205)$, and $S$. Corvallis $(\mathrm{n}=90)$, using pulsed-field gel electrophoresis. Isolates were collected from several sources, primarily from chicken-derived samples, in the KyushuOkinawa region of Japan between 1989 and 2005. S. Enteritidis isolates displayed 51 distinct PFPs (E-PFPs), with 92 (52.0\%) and $32(18.1 \%)$ isolates displaying types EPFP1 and E-PFP10, respectively. The 205 $S$. Infantis isolates showed 54 distinct PFPs (I-PFPs), with 87 (42.4\%) and 36 (17.6\%) isolates being I-PFP4 and I-PFP2, respectively. I-PFP18 was the dominant I-PFP of layer chicken isolates across a 5-year period. Fourteen distinct $S$. Corvallis PFPs were detected. Simpson's index results for the genetic diversities of $S$. Enteritidis, $S$. Infantis, and $S$. Corvallis isolates were 0.70 , 0.79 , and 0.78 , respectively. None of the EPFPs or I-PFPs of layer chicken isolates overlapped with those of broiler chicken isolates, and the dominant clonal lines existed for $>10$ years. In conclusion, limited PFP diversities were detected amongst $S$. Enteritidis, $S$. Infantis, and $S$. Corvallis isolates of primarily chicken-derived origins in the Kyushu-Okinawa region of Japan. Therefore, it is important to take into account these limitations in PFP diversities in epidemiological analyses of Salmonella outbreaks.

\section{Introduction}

Pulsed-field gel electrophoresis (PFGE) subtype diversity within non-typhoidal Salmonella serovars can influence epidemiological analyses using pulsed-field profiling of Salmonella isolates, especially those using isolates from disease outbreaks. Pulsed-field profiling of non-typhoidal Salmonella strains is useful for public health as it enables detection of geographically dispersed outbreaks of this important diarrheal pathogen (Mishu Allos et al., 2004). However, this type of analysis is complicated by the fact that some pulsedfield profiles (PFPs) may be common and widely distributed (Lindqvist and Pelkonen, 2007; Swaminathan et al., 2001). For example, Pang et al. (2007) found limited genetic diversity amongst Salmonella enterica subspecies enterica serovar Enteritidis isolates in Taiwan and Germany. They observed that a single major worldwide clone of $S$. Enteritidis was present in several sources, including deer, pigs, fish, chickens, horses, other birds, rodents, eggs, corn, mushrooms, soil, and water, when PFPs were determined using three restriction enzymes.

Three serovars were chosen for analysis in the current study because these three serovars are relatively important for food hygiene. $S$. Infantis is the most common food-associated serovar in Japan, particularly in chicken meat (Murakami et al., 2001), and is also one of the most important serovars for public health (Murakami et al., 2007). S. Enteritidis is also commonly associated with human disease (NIID, 2006), and is related to layer chickens (Humphrey 2006). S. Corvallis is not a dominant serovar but is routinely isolated from chickens and poultry products (Murakami et al. 2001). While analysis of current PFP data is very important for public health, recording old PFP data is also important from a historical viewpoint. In addition, comparing historical PFP data with that from current isolates can provide important information, such as identification of recurring PFPs. PFGE data for the three chosen serovars is available from several previous papers; however, no long-term analysis has been carried out (Murakami et al., 1999a, 1999b, 2001, 2007; Noda et al., 2010, 2011). Therefore, we carried out a relatively longterm (1989-2005) analysis of historical isolates using PFGE. The aim of the current study was to determine the PFP diversity of $S$. Enteritidis, $S$. Infantis, and $S$. Corvallis
Correspondence: Koichi Murakami, Infectious Disease Surveillance Center, National Institute of Infectious Diseases, 4-71 Gakuen, Musashi-murayama, Tokyo 2080011, Japan.

Tel: +81-42-848-7132; Fax: +81-42-565-3315. E-mail:kmuraka@nih.go.jp

Key words: Salmonella Enteritidis; Salmonella Infantis; Salmonella Corvallis; Pulsed-field gel electrophoresis; Pulsed-field profile.

Conflict of interest: the authors declare no potential conflict of interest.

Funding: this work was supported in part by a grant from the Japanese Society for the Promotion of Science (KAKENHI; no. 15K08794), and by the Research Program on Emerging and Re-emerging Infectious Diseases from the Japan Agency for Medical Research and Development, AMED (17fk0108106j0101).

Acknowledgments: we are grateful to the late Mr. Toshihiro Mako, Fukuoka City Institute for Hygiene and the Environment, for his invaluable advice. We thank Dr. Maeda for providing selected S. Corvallis isolates, and Dr. Takenaka and Dr. Sera, Fukuoka Institute of Health and Environmental Sciences (FIHES), for their invaluable advice. We also thank Dr. Saeki and Ms Maruta of FIHES, and Ms. Doi and Ms. Yamada of National Institute of Infectious Diseases, for their technical assistance. We thank Tamsin Sheen, PhD, from Edanz Group (www.edanzediting.com/ac) for editing a draft of this manuscript

Received for publication: 22 May 2017. Revision received: 13 July 2017.

Accepted for publication: 5 September 2017.

This work is licensed under a Creative Commons Attribution-NonCommercial 4.0 International License (CC BY-NC 4.0).

(C) Copyright K. Murakami et al., 2017 Licensee PAGEPress, Italy Italian Journal of Food Safety 2017; 6:6808 doi:10.4081/ijfs.2017.6808

isolates collected from several sources, mainly chicken-derived samples, in the Kyushu-Okinawa region of Japan over a 17-year period.

\section{Materials and Methods}

\section{Isolates}

All isolates $(n=472)$ belonging to the three serovars are listed in Table 1. Isolates were selected for long-term assessment of clonal lines, and included nearly all samples 
from a collection of the three serovars from the Fukuoka Institute of Health and Environmental Sciences (FIHES), Dazaifu, Fukuoka Prefecture, in the KyushuOkinawa region of Japan. The KyushuOkinawa region consists of eight prefectures, including Japan's third largest island, and is located southwest of the main island of Honshu. Although the majority of isolates and their original samples were obtained from the Kyushu-Okinawa region, nine isolates were obtained from other regions. Sample details are documented in Table 1.

$S$. Enteritidis isolates $(\mathrm{n}=177)$ from 173 samples were collected between 1989 and
2005 (Tables 2 and 3). S. Infantis isolates $(\mathrm{n}=205)$ from 184 samples, and $S$. Corvallis isolates $(\mathrm{n}=90)$ from 88 samples, were collected between 1995 and 2005 (Tables 2 and 3). S. Enteritidis PFP (E-PFP) data for 64 isolates collected between 1989 and 2004, $S$. Infantis PFP (I-PFP) data for 134 isolates collected between 1995 and 2005, and $S$. Corvallis PFP (C-PFP) data for 16 isolates collected from food handlers in 1999 and 2000 were previously reported in a different context (Murakami et al., 1999a, 1999b, 2001, 2007; Noda et al., 2010, 2011), and were re-analyzed in the current study by PFGE for comparison with the newly tested isolates.
Isolates belonged to the following five categories: human, food, slaughterhouse, farm and shell egg production environment, and environmental inspection. Human samples included outbreak isolates from symptomatic patients, food handler isolates, and sporadic case isolates from symptomatic patients (Table 1). The outbreak isolates were obtained from outbreaks in Fukuoka Prefecture, and were isolated at the FIHES. The food handler isolates were obtained from a clinical laboratory and serotyped at the FIHES (Murakami et al., 2007), except for one $S$. Infantis isolate, which was isolated at the FIHES. The sporadic case isolates were also obtained from a clinical laborato-

Table 1. Salmonella isolates examined in the present study.

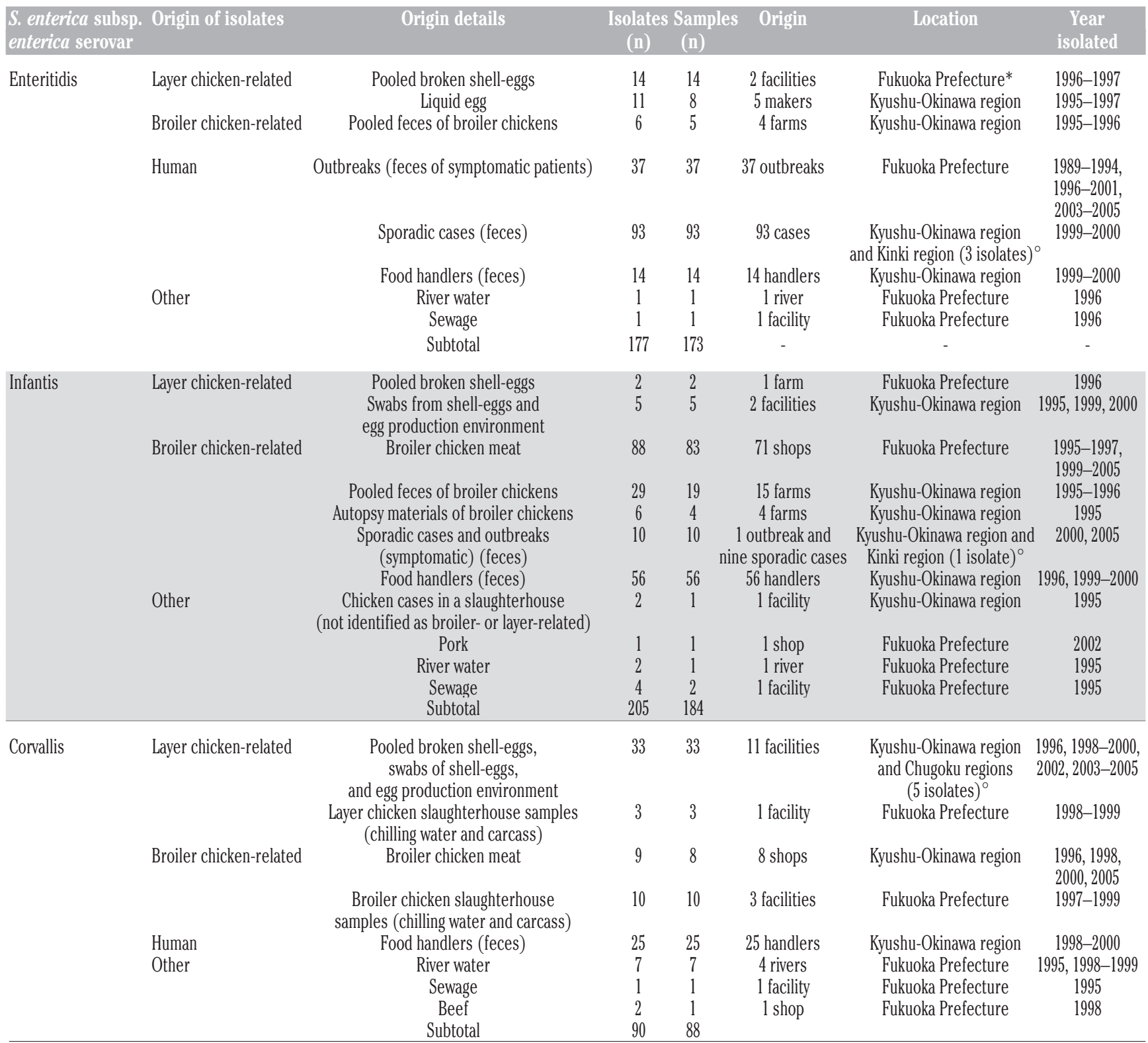


Table 2. Pulsed-field profiles of Salmonella isolates and their origins.

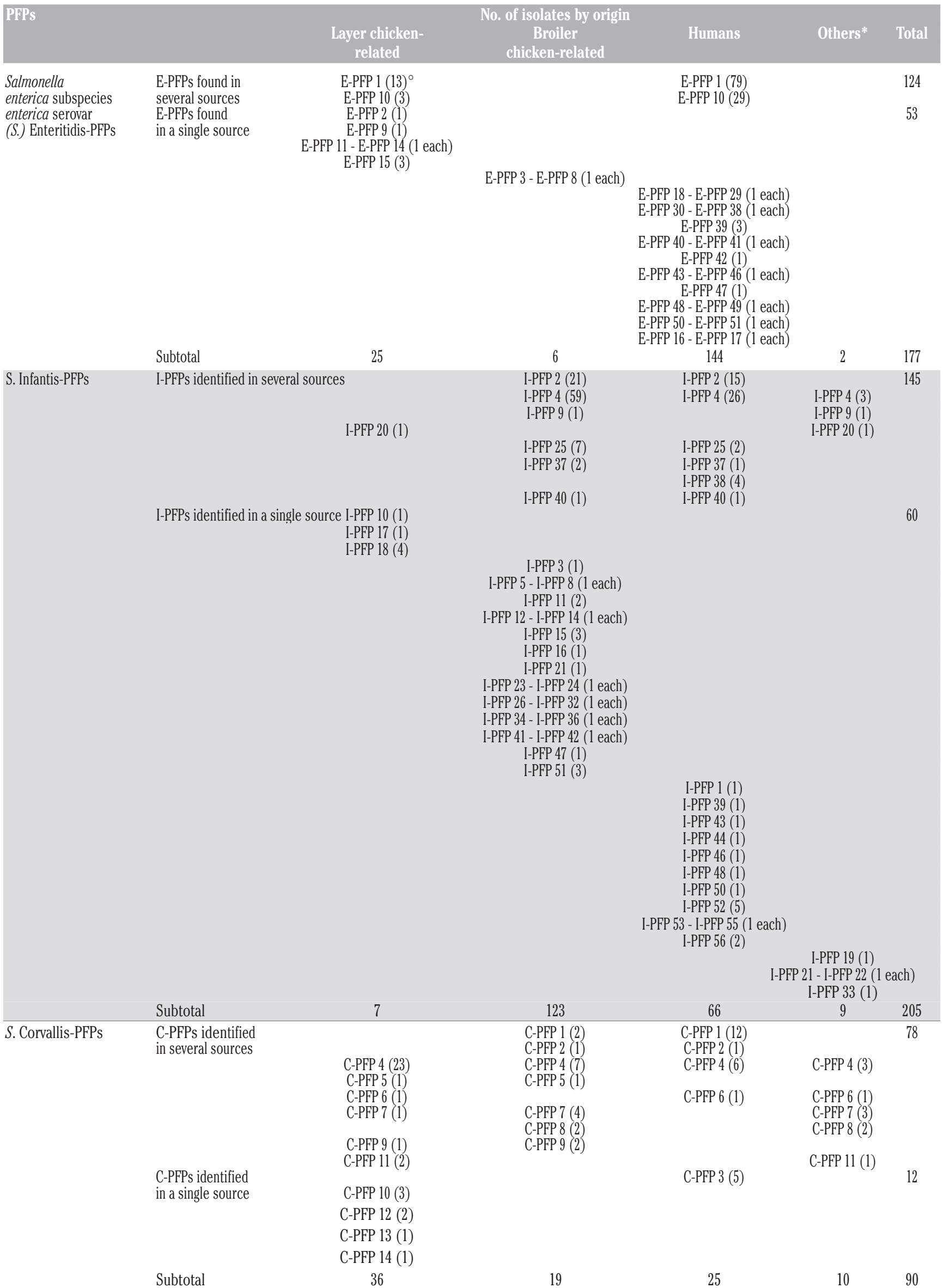

PFPs, pulsed-field profiles. *Including $S$. Infantis PFPs from broiler chicken slaughterhouse samples (chilling water and carcass); ${ }^{\circ}$ no. of isolates. 
ry and serotyped at the FIHES (Murakami et al., 2007). The sporadic case samples were obtained from periodic inspections of food handlers in the Kinki (three $S$. Enteritidis isolates and one $S$. Infantis isolate) and Kyushu-Okinawa regions. In the food category, isolates were collected from beef, broiler meat, liquid-egg, and pork (Table 1). These food isolates were obtained during a food hygiene inspection survey for foodborne pathogens in Fukuoka Prefecture, and were isolated at the FIHES. In the slaughterhouse category, isolates were collected from broiler slaughterhouse samples (chilling water and carcass), chicken samples from a slaughterhouse (not identified as broiler- or layer-derived), and layer slaughterhouse samples (chilling water and carcass) (Table 1). These isolates were obtained from five slaughterhouses in the Kyushu-Okinawa region and were isolated at the Fukuoka Prefectural Meat Safety Inspection Center, Chikushino, Fukuoka Prefecture, and at another laboratory in Fukuoka Prefecture.
In the farm and shell egg production environment category, isolates were grouped into those from swabs from egg shells and the egg production environment, pooled broken shell eggs, pooled feces of broiler chickens, and necropsy materials from broilers (Table 1). The swabs from egg shells and egg production environment isolates and the pooled broken shell egg isolates were obtained from 32 chicken farms and three egg-packing facilities. Thirty-one of the 32 farms that donated samples were located in the Kyushu-Okinawa regions, while one farm that donated four samples of $S$. Corvallis was outside of the region. Some of these isolates were provided by a livestock hygiene service center. Two of the three egg-packing facilities (facilities A and B) provided isolates from swab samples obtained from eggshells and the egg production environment. Facility A packs 360,000 eggs per day, and these eggs are supplied from nine farms. Facility B has an integrated operation with 240,000 eggs supplied daily from their own farm. Retail data were not available from farms, or for the third egg-packing facility.

Finally, in the environment inspection category, isolates were obtained from river water and sewage samples (Table1). The samples were obtained from Fukuoka Prefecture, and bacteria were isolated at the FIHES (Murakami et al., 2001). These isolates were re-categorized into the following four groups: layer chicken-related, broiler chicken-related, human, and other isolates (Table 2).

One isolate from each sample was analyzed, except in the case of four $S$. Enteritidis-containing samples, $21 \mathrm{~S}$. Infantis-containing samples, and two $S$. Corvallis-containing samples for which two isolates from each sample were analyzed. In these samples, two representative isolates showed different PFPs, indicating the presence of more than one strain. Therefore, both isolates were analyzed from these 27 samples (totaling 54 isolates).

Table 3. Chronological appearance of each pulsed-field profile of Salmonella enterica subspecies enterica serovars Enteritidis ( $S$. Enteritidis), $S$. Infantis, and $S$. Corvallis over a 17 -year period.

\begin{tabular}{|c|c|c|c|c|c|c|c|c|c|c|c|c|c|c|c|c|c|c|c|c|c|}
\hline & & & 1989 & 1990 & 1991 & 1992 & 1009 & 1994 & 1995 & & & & 1999 & 2000 & 2001 & 2002 & 2003 & 2004 & 2005 & Total & $1(\%)$ \\
\hline \multirow[t]{2}{*}{$\begin{array}{l}\text { S. Enteritidis } \\
\text { (177 isolates) }\end{array}$} & $\begin{array}{l}\text { E-PFPs observed } \\
\text { for } 2 \text { or more } \\
\text { years }\end{array}$ & $\begin{array}{l}\text { E-PFP } 1 \\
\text { E-PFP } 10\end{array}$ & & 1 & 1 & & & 1 & & $\begin{array}{l}7 \\
2\end{array}$ & $\begin{array}{c}10 \\
2\end{array}$ & 4 & $\begin{array}{l}13 \\
5\end{array}$ & $\begin{array}{l}50 \\
22\end{array}$ & $\begin{array}{l}1 \\
1\end{array}$ & & 1 & 2 & 1 & $\begin{array}{l}92 \\
32\end{array}$ & $\begin{array}{l}(52.0) \\
(18.1)\end{array}$ \\
\hline & $\begin{array}{l}\text { The remaining } 49 \\
\text { E-PFPs observed } \\
\text { in a single year only }\end{array}$ & & 1 & & & 2 & 3 & 4 & 4 & 9 & 5 & & 10 & 13 & 1 & & & & 1 & 53 & (29.9) \\
\hline $\begin{array}{l}\text { S. Infantis } \\
\text { (205 isolates) }\end{array}$ & $\begin{array}{l}\text { I-PFPs observed for } \\
2 \text { or more years } \\
\text { The remaining } \\
44 \text { I-PFPs observed } \\
\text { in a single year only }\end{array}$ & $\begin{array}{l}\text { I-PFP } 2 \\
\text { I-PFP } 4 \\
\text { I-PFP 9 } \\
\text { I-PFP } 15 \\
\text { I-PFP } 18 \\
\text { I-PFP } 20 \\
\text { I-PFP } 25 \\
\text { I-PFP } 37 \\
\text { I-PFP } 51 \\
\text { I-PFP } 52\end{array}$ & & & & & & & $\begin{array}{c}4 \\
16 \\
1 \\
1 \\
1\end{array}$ & $\begin{array}{c}4 \\
10 \\
1 \\
2\end{array}$ & 4 & & $\begin{array}{l}2 \\
1 \\
1 \\
\\
4 \\
1\end{array}$ & $\begin{array}{c}15 \\
32 \\
1 \\
1 \\
\\
2 \\
2 \\
1 \\
1 \\
18\end{array}$ & $\begin{array}{l}1 \\
2 \\
1\end{array}$ & $\begin{array}{l}2 \\
6\end{array}$ & $\begin{array}{l}6 \\
2\end{array}$ & $\begin{array}{l}1 \\
5\end{array}$ & $\begin{array}{l}2 \\
7\end{array}$ & $\begin{array}{c}36 \\
87 \\
2 \\
3 \\
4 \\
2 \\
9 \\
3 \\
3 \\
5 \\
51\end{array}$ & $\begin{array}{c}(17.6) \\
(42.4) \\
(1.0) \\
(1.5) \\
(2.0) \\
(1.0) \\
(4.4) \\
(1.5) \\
(1.5) \\
(2.4) \\
(24.9)\end{array}$ \\
\hline $\begin{array}{l}\text { S. Corvallis } \\
\text { (90 isolates) }\end{array}$ & $\begin{array}{l}\text { C-PFPs observed for } \\
\text { two or more years } \\
\text { The remaining } 4 \text { C-PF } \\
\text { observed in a single y }\end{array}$ & $\begin{array}{l}\text { C-PFP } 1 \\
\text { C-PFP } 3 \\
\text { C-PFP } 4 \\
\text { C-PFP } 5 \\
\text { C-PFP } 6 \\
\text { C-PFP } 7 \\
\text { C-PFP } 8 \\
\text { C-PFP 9 } \\
\text { C-PFP } 10 \\
\text { C-PFP } 11 \\
\text { PPs } \\
\text { year only }\end{array}$ & & & & & & & 2 & 2 & $\begin{array}{l}1 \\
1\end{array}$ & $\begin{array}{c}1 \\
16 \\
1 \\
7\end{array}$ & $\begin{array}{c}10 \\
2 \\
3 \\
2 \\
2 \\
1 \\
\\
1\end{array}$ & $\begin{array}{l}3 \\
3\end{array}$ & & 2 & 1 & $\begin{array}{l}1 \\
1 \\
2\end{array}$ & 1 & $\begin{array}{c}14 \\
5 \\
39 \\
2 \\
3 \\
8 \\
4 \\
3 \\
3 \\
3\end{array}$ & $\begin{array}{c}(15.6) \\
(5.6) \\
(43.3) \\
(2.2) \\
(3.3) \\
(8.9) \\
(4.4) \\
(3.3) \\
(3.3) \\
(3.3)\end{array}$ \\
\hline
\end{tabular}




\section{Pulsed-field gel electrophoresis}

Clonal lineages of the $S$. Enteritidis, $S$. Infantis, and $S$. Corvallis serovars were determined by PFGE analysis. PFGE was performed as described previously (Murakami et al. 1999b; Murakami et al. 2007), with the following modifications. After preparation for restriction endonuclease digestion, the DNA in each $S$. Corvallis plug was digested with 20 units of $\mathrm{Xba \textrm {I }}$ (Takara Bio, Otsu, Japan) at $37^{\circ} \mathrm{C}$ for $15 \mathrm{~h}$, and then electrophoresed at $200 \mathrm{~V}$ for $22 \mathrm{~h}$, with a switched pulse time of 5-50 $\mathrm{s}$ at $14^{\circ} \mathrm{C}$. Plugs of $S$. Enteritidis and $S$. Infantis were then digested with 20 units of $B \ln \mathrm{I}$ (Takara Bio) at $37^{\circ} \mathrm{C}$ for $15 \mathrm{~h}$, and electrophoresis was performed at $200 \mathrm{~V}$ for $24 \mathrm{~h}$ with a switched pulse time of $2-43.1 \mathrm{~s}$ at $14^{\circ} \mathrm{C}$. DNA fragment patterns were assessed visually, and different PFPs were assigned based on the presence or absence of bands. Similarity and cluster analyses were performed using the Dice coefficients of similarity and an unweighted pair group method with average linkage, respectively, using FPQuest Software (Bio-Rad Laboratories, Hercules, CA, USA). $S$. Enteritidis strain ATCC 13076, S. Infantis strain ATCC 51741, and $S$. Corvallis strain K54-1 were used as respective reference strains in all analyses.

\section{Simpson's index analysis}

Simpson's index of diversity (Hunter and Gaston 1988) was used to evaluate genetic diversity within each serovar. This index is given by the following equation:

$=1-\left(\sum n(n-1)\right) /(\mathrm{N}(\mathrm{N}-1))$

where $n$ is number of isolates belonging to the $n$th type and $\mathrm{N}$ is total number of isolates in the same population. A value of 1 indicates infinite diversity, and a value of 0 indicates no diversity.

\section{Statistical analysis}

PFP associations between layer and broiler chicken isolates of each of the three serovars were evaluated using the Wilcoxon rank-sum test (Hollander and Wolfe, 1973) using SAS Software version 9.1.3 (SAS Institute, Cary, NC, USA) to assess population differences between the two host types.

\section{Results}

\section{Pulsed-field gel electrophoresis}

The three serovars showed limited PFP diversities. Although the $S$. Enteritidis isolates displayed 51 distinct PFPs (Tables 1 and 2), $92(52.0 \%)$ and $32(18.1 \%)$ isolates displayed E-PFP1 and E-PFP10, respectively. In particular, E-PFP1 was detected every year except one between 1990 and 2005 (Table 3), and no E-PFPs other than E-PFP1 and EPFP10 were detected in more than one year (Table 3). No E-PFPs were shared between layer chicken isolates (pooled broken shell eggs and liquid-egg isolates) and broiler chicken isolates (pooled feces) (Tables 1 and 2). In addition, many E-PFPs associated with broiler-derived isolates grouped together in clades that were distinct from the layer chicken isolates (Appendix Figure 1).
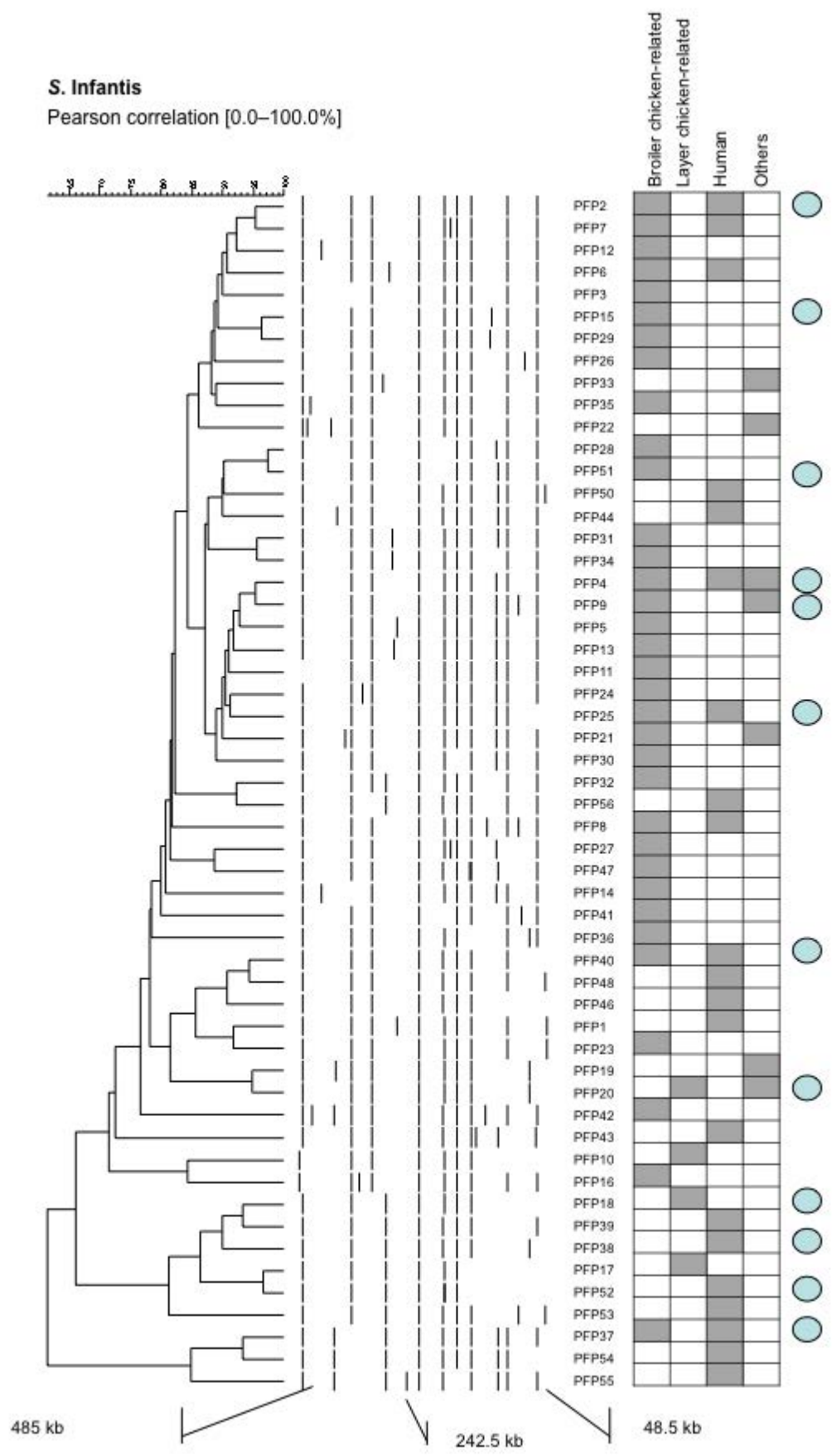

Figure 1. Dendrogram of pulsed-field profiles for Salmonella enterica subspecies enterica serovar Infantis (I-PFPs) following BlnI digestion. Fifty-four different I-PFPs were obtained from 205 isolates. Numbers indicate fragment sizes. Origins of each I-PFP are indicated. I-PFPs with closed circles were observed in two or more years. Some I-PFPs were assigned numbers in our previous study, and thus are not numbered consecutively. The scale indicates the percentage similarity, as determined using Dice coefficients. 
The $205 S$. Infantis isolates showed 54 I-PFPs, with 87 (42.4\%) and 36 (17.6\%) isolates being I-PFP4 and I-PFP2, respectively (Table 1, Figure 1). I-PFP2 was found in isolates from both broiler chicken and human samples, while I-PFP4 appeared in isolates from pork, broiler chickens, and humans (Table 2). I-PFP18 was the dominant I-PFP of layer chicken isolates across a 5 -year period (Table 3). Among the 54 IPFPs, 10 were detected over multi-year periods, and 44 (51 isolates) were each found in a single year. Some I-PFPs were assigned numbers in our previous study, and thus are not numbered consecutively in this study. Layer and broiler chicken isolates shared no common I-PFPs (Tables 1 and 2). Many layer chicken isolate-associated IPFPs grouped together in clades that were distinct from those of the broiler chicken isolates (Figure 1).

Fourteen distinct $S$. Corvallis C-PFPs were detected (Tables 1 and 2, and Appendix Figure 2). C-PFP4 was the dominant C-PFP for over 10 years, and was found in 39 (43.4\%) of 90 isolates (Table 3). Among the 14 C-PFPs, nine were present over multi-year periods (Table 3 ).

\section{Analyses using Simpson's index}

Simpson's index results for the genetic diversities of $S$. Enteritidis, $S$. Infantis, and $S$. Corvallis were $0.70,0.79$, and 0.78 , respectively.

\section{Statistical analysis}

PFP patterns of the $S$. Infantis isolates were significantly different $(\mathrm{P}<0.001)$ between isolates associated with layer and broiler chickens. No statistical differences between these groups were found for $S$. Enteritidis $(\mathrm{P}=0.147)$ and $S$. Corvallis $(\mathrm{P}=0.597)$.

\section{Discussion}

Our study had three major findings. First, Simpson's index analysis indicated that there was little PFP diversity within the serovars. Second, dominant PFPs of $S$. Enteritidis, $S$. Infantis, and $S$. Corvallis were observed in both chicken- and humanderived strains. The dominant PFPs of $S$. Enteritidis and $S$. Infantis persisted for a relatively long time ( $>10$ years). Finally, of the population structures of the PFPs for the three serovars, only the I-PFPs of broiler chicken isolates differed significantly from those of layer chicken isolates, based on the Wilcoxon rank-sum test. Moreover, none of the PFPs detected for $S$. Enteritidis and $S$. Infantis from layer chicken isolates overlapped with those from broiler chicken iso- lates. Based on these findings, we concluded that one E-PFP was dominant in the Kyushu-Okinawa region of Japan (Table 3), and that $S$. Infantis from several sources showed limited PFP diversity.

Comparing Simpson's index results determined in the current analysis to those from other countries, the diversity of the $S$. Enteritidis isolates $(0.70)$ was lower than that determined in previous studies: 0.76 for a general US survey (using $B \ln \mathrm{I}$ ) (Zheng et al., 2007), 0.79 in Minnesota, USA (using XbaI) (Rounds et al., 2010), and 0.79 in France (using $X b a \mathrm{I}$ ) (Kérouanton et al., 2007). The value for $S$. Infantis (0.79) was also lower than those reported in other studies: 0.97 in Minnesota (using $X b a \mathrm{I}$ ) (Rounds et al., 2010) and 0.88 in France (using XbaI) (Kérouanton et al., 2007). The differences between the current and previous studies may stem from physiographical differences or clonalities of the serovars. We collected samples mainly from the Kyushu-Okinawa region, which may be limited in comparison with other studies. However, the values determined in all nontyphoidal Salmonella studies are lower than those for other salmonellae or foodborne pathogens such as $S$. Typhi (0.952) (Kubota et al., 2005) or Escherichia coli O157 (0.98) (Avery et al., 2002), illustrating the limited clonal populations of these three Salmonella serovars in the KyushuOkinawa region of Japan.

There are several explanations for the observed lower genetic diversity of the Salmonella serovars examined in the current study. Hauser et al. suggested genetic stability or broad dissemination of a recent ancestor as possible reasons for the high clonality of $S$. Infantis (Hauser et al., 2012). However, another reason might be the limited genealogical diversity of industrial poultry chickens. Almost all commercial layer and broiler chicken flocks in many developed countries, including Japan, are derived from a few great-grandparental flocks that are imported from limited countries (Leeson and Summers, 2000), likely limiting the impact of genealogical factors. Therefore, $S$. Enteritidis and $S$. Infantis serovars might have evolved to adapt to the limited chicken genetic population, as is described by the theory of co-evolution (Pfennig, 2001). If all members of a population adapt to an evolutionarily stable state, no mutations can evolve under the influence of natural selection according to MaynardSmith (1982).

\section{Conclusions}

Limited PFP diversities were detected in $S$. Enteritidis, $S$. Infantis, and $S$. Corvallis isolates collected between 1989 and 2005 from primarily chicken-derived origins in the Kyushu-Okinawa region of Japan. It is important to account for these limited PFP diversities in epidemiological analyses of outbreaks caused by these Salmonella serovars.

\section{References}

Avery SM, Liebana E, Reid CA, Woodward MJ, Buncic S, 2002. Combined use of two genetic fingerprinting methods, pulsed-field gel electrophoresis and ribotyping, for characterization of Escherichia coli O157 isolates from food animals, retail meats, and cases of human disease. J Clin Microbiol 40:2806-12.

Hauser E, Tietze E, Helmuth R, Junker E, Prager R, Schroeter A, Rabsch W, Fruth A, Toboldt A, Malorny B, 2012. Clonal dissemination of Salmonella enterica serovar Infantis in Germany. Foodborne Pathog Dis 9:352-60.

Hollander M, Wolfe DA, 1973. Nonparametric statistical methods. John Wiley \& Sons Inc., New York, NY, USA.

Humphrey T, 2006. Public health aspects of Salmonella enterica in food production. In: P Mastroeni P, Maskell D eds. Salmonella infections, clinical, immunological and molecular aspects. Cambridge University Press, Cambridge, UK, pp 89-116.

Hunter PR, Gaston MA, 1988. Numerical index of the discriminatory ability of typing systems: an application of Simpson's index of diversity. J Clin Microbiol 26:2465-6.

Kérouanton A, Marault M, Lailler R, Weill FX, Feurer C, Espié E, Brisabois A, 2007. Pulsed-field gel electrophoresis subtyping database for foodborne Salmonella enterica serotype discrimination. Foodborne Pathog Dis 4:293303.

Kubota K, Barrett TJ, Ackers ML, Brachman PS, Mintz ED, 2005. Analysis of Salmonella enterica serotype Typhi pulsed-field gel electrophoresis patterns associated with international travel. J Clin Microbiol 43:1205-9.

Leeson S, Summers JD, 2000. Broiler breeder production. University books, Guelph, Canada.

Lindqvist N, Pelkonen S, 2007. Genetic surveillance of endemic bovine Salmonella Infantis infection. Acta Vet Scand 49:15. 
Maynard-Smith J, 1982. Evolution and the theory of games. Cambridge University Press, Cambridge, UK.

Mishu Allos B, Moore MR, Griffin PM, Tauxe RV, 2004. Surveillance for sporadic foodborne disease in the 21 st century: the FoodNet perspective. Clin Infect Dis. 38(Suppl.3):115-20.

Murakami K, Horikawa K, Ito T, Otsuki K, 2001. Environmental survey of salmonella and comparison of genotypic character with human isolates in Western Japan. Epidemiol Infect 126:159-71.

Murakami K, Horikawa K, Otsuki K, 1999a. Epidemiological analysis of Salmonella enteritidis from human outbreaks by pulsed-field gel electrophoresis. J Vet Med Sci 61:439-42.

Murakami K, Horikawa K, Otsuki K, 1999b. Genotypic characterization of human and environmental isolates of Salmonella choleraesuis subspecies choleraesuis serovar Infantis by pulsedfield gel electrophoresis. Microbiol
Immunol 43:293-6.

Murakami K, Ishihara T, Horikawa K, Oda T, 2007. Features of Salmonella serovars among food handlers in Kyushu, Japan. New Microbiol 30:1559.

NIID, 2006. National Institute of Infectious Diseases and Tuberculosis and Infectious Diseases. Salmonellosis in Japan as of June 2006. Infect Agents Surv Rep 27:191-2.

Noda T, Murakami K, Asai T, Etoh Y, Ishihara T, Kuroki T, Horikawa K, Fujimoto S, 2011. Multi-locus sequence typing of Salmonella enterica subsp. enterica serovar Enteritidis strains in Japan between 1973 and 2004. Acta Vet Scand 53:38.

Noda T, Murakami K, Ishiguro Y, Asai T, 2010. Chicken meat is an infection source of Salmonella serovar Infantis for humans in Japan. Foodborne Pathog Dis 7:727-35.

Pang JC, Chiu TH, Helmuth R, Schroeter A,
Guerra B, Tsen HY, 2007. A pulsed field gel electrophoresis (PFGE) study that suggests a major world-wide clone of Salmonella enterica serovar Enteritidis. Int J Food Microbiol 116:305-12.

Pfennig KS, 2001. Evolution of pathogen virulence: the role of variation in host phenotype. Proc Biol Sci 268:755-60.

Rounds JM, Hedberg CW, Meyer S, Boxrud DJ, Smith KE, 2010. Salmonella enterica pulsed-field gel electrophoresis clusters, Minnesota, USA, 2001-2007. Emerg Infect Dis 16:1678-85.

Swaminathan B, Barrett TJ, Hunter SB, Tauxe RV, CDC PulseNet Task Force, 2001. PulseNet: the molecular subtyping network for foodborne bacterial disease surveillance, United States. Emerg Infect Dis 7:382-9.

Zheng J, Keys CE, Zhao S, Meng J, Brown EW, 2007. Enhanced subtyping scheme for Salmonella enteritidis. Emerg Infect Dis 13:1932-5. 